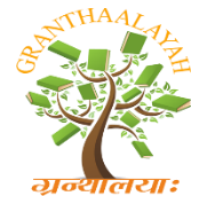

\author{
INTERNATIONAL JOURNAL OF R
GRANTHAALAYAH \\ A knowledge Repository
}

Management

\title{
A STUDY ON FUTURE OF MOBILE BASED PAYMENT FOR GOVERNMENT SERVICES IN INDIA
}

\author{
Ashish Jaiswal *1 \\ ${ }^{* 1}$ Research Scholar, Department of Management, Sri Satya Sai University of Technology \& \\ Medical Sciences, Sehore, Madhya Pradesh, India
}

\begin{abstract}
Digital India programme of Government of India has promoting and encouraging the usage of digital payments for the various goods and services being availed by the citizens. The Government wants to develop a Digitally Empowered economy through the cashless transactions. As far as government agencies are concerned, mobile based payment is a noteworthy development on various domains, because it is going to increase ease and productivity for both the agencies and citizens themselves. Citizens who are using the Government services are concerned of the privacy of the data and information. Government needs to evaluate the procedure from beginning to end to ensure it meets strict standards and keeps information private. Poor literacy levels are a problem with this technology. The mobile payment services have to be effective in terms of usability, cost, efficiency, interoperability and security for transactions of all categories of citizens. Mobile payments options needs to be available even on low end mobile handsets.
\end{abstract}

Keywords: Mobile Payment; Digital India; UPI; BHIM; Wallet; Banking.

Cite This Article: Ashish Jaiswal. (2020). "A STUDY ON FUTURE OF MOBILE BASED PAYMENT FOR GOVERNMENT SERVICES IN INDIA.” International Journal of Research Granthaalayah, 8(2), 118-123. https://doi.org/10.29121/granthaalayah.v8.i2.2020.192.

\section{Introduction}

Digital India programme of Government of India has promoting and encouraging the usage of digital payments for the various goods and services being availed by the citizens. After demonetization in November 2016 the Government wants to develop a Digitally Empowered economy through the cashless transactions. There are various modes and types of payment options available through mobile and apps using which the citizens can pay for the various services. Some of them are Payment Apps, Wallets, Unified Payments Interface (UPI), Cards, Unstructured Supplementary Service Data (USSD), Aadhaar Enabled Payment System (AEPS), Bharat Interface for Money (BHIM) app, Mobile Banking.

India is one of the largest market for telecommunications market in India having 128 Crore mobile phones and world's largest market for mobile payments which reach even to the remote villages. 
As far as government agencies are concerned, mobile based payment is a noteworthy development on various domains, because it is going to increase ease and productivity for both the agencies and citizens themselves.

Various government services wherein citizen needs to pay government are:

- Utility Bills

- Taxes by citizens

- Taxes by business community

- Challan

- Duties

- Fee for availing citizen services like license, certificates

- Fee by students

- Fare for railway, buses and metro etc.

- Toll charges

\section{Objective of the Study}

1) To assess the current status of mobile based payments for government services in India

2) To study the efforts being made to increase the mobile based payments

3) To study the factors affecting access to mobile based payments and challenges

4) To study the role of mobile payments in society.

\section{Methodology of the Study}

Secondary research was conducted to assess the status of mobile based payments for government services. The data was collected from secondary sources such as research papers, published articles, journals and websites of NPCI, Digital India, RBI, etc.

\section{Electronic Payment and Receipts in Government}

Government of India through Ministry of Electronic and Information Technology, has envisaged anywhere anytime access to information and services all across the country through web-and mobile enablement, particularly for remote and rural areas of country. Ministry further envisages common ICT infrastructure that will provide entire transactional understanding for a citizen usage, businesses community along with internal functions of government, which comprises of accessing several services through internet via online payment with payment gateway interface.

Electronic Payment and Receipts framework of Ministry is proposed for State Governments, Public Sector Undertakings, Autonomous Bodies and Corporations to expedite implementation of suitable mechanism for enabling electronic payments and receipts for the benefit of citizens.

This framework provide guidelines to the Departments with the following objectives:

i. Assess several services including payments and receipts based on the types of services and status of digital payment enablement mechanism

ii. Make available actionable guidelines for total implementation of electronic payment modes for each type of service over several payment channels for citizens 
iii. Provide recommendations on arrangement with various service providers for enabling online payments

Trinity of reforms i.e. Jan Dhan Yojana, Aadhaar initiative of UIDAI and Mobile number (JAM) is one of the biggest area of reform done in India. To enable the digital payment financial inclusion is one of the main concern of Government. Government Departments need to implement the modes of electronic payments \& receipts for their internal and external functions thus making the process convenient for citizens.

Some of the steps taken under this framework are:

i. Promotion of Card / Digital Transactions in Government Payments and Collections

ii. Measures for Wider Adoption of Card/Digital Transactions

iii. Creating Acceptance Infrastructure

iv. Encouraging Mobile Banking/ Payment Channels

v. Awareness and Grievance Redressal

\section{Progress in Mobile Based Payment Implementation}

In India as per global advisory KPMG report the Digital payments are witnessing blooming growth with a compound annual growth rate (CAGR) of $12.7 \%$ in the number of non-cash transactions. The report mentioned that QR-code based wallet acceptance due to low setting up costs has played an important role in mass adoption among citizen and business which has increased convenience for customers. About close to 1.5 million digital payment acceptance sites in 2016-17, the number of business accepting digital payments modes has augmented to over 10 million, in two to three years' time.

In its 2021 vision document the Reserve Bank of India has a prediction that there will be an increase of $50 \%$ in mobile-based payment transactions. This swing can be accredited to dynamic factors such as strong payment infrastructure, development of form factors, accessibility of structured data, change in consumer manners and the government's vision of transforming India into a cashless economy.

Table 1: Customers using Mobile Wallets and Number of Download the difference types of Mobile Wallets

\begin{tabular}{|l|l|}
\hline Mobile Wallets & Number of Downloads \\
\hline Paytm & 50 Million \\
\hline Mobikwik & 10 million \\
\hline BHIM & 10 million \\
\hline SBI Buddy & 10 million \\
\hline Google's Tez & 10 million \\
\hline Freecharge & 10 million \\
\hline PhonePe & 10 million \\
\hline ICICI Pockets & 5 million \\
\hline Oxigen & 5 million \\
\hline HDFC PayZapp & 5 million \\
\hline
\end{tabular}


In India as per report by Nielsen and Internet and Mobile Association of India (IAMAI) as on March 31, 2019 monthly active internet users were 451 Million, in urban areas $72 \%$ of urban Internet users i.e. approximately 139 Million use internet daily. While in rural areas $57 \%$ i.e. approximately 109 Million of the rural internet users' access the internet daily. ASSOCHAM-PwC joint study report mentions that by 2022 the number of smartphone users in India is likely to double to 859 million from 468 million users in 2017.

All these figures predict that the next generation of digital payments is likely to have big impact on the economic eco system of the country and majority of payment will be done using mobile.

\section{Benefits in the Usage of Mobile Based Payments for the Government Services}

There are many benefits considering the ecosystem of the government machinery and our society, some of them are:

- Ease of usage: This process improves the ease of conducting card/digital transactions for a citizen who can operate his mobile effectively.

- Risk reduction: Using the digital media for making and receiving payments it reduce the risks and costs of handling cash at all the levels.

- Cost of managing cash: When transaction are done digitally it reduces costs of handling and managing cash at various levels in the economy.

- Record Keeping: All the digital transactions build transactions history which enables the improvement in the financial inclusion and credit access.

- Tax Collection: Digital and mobile based payment process reduce tax avoidance as all the transactions are tracked and database of such transactions can be accessed by the tax authorities.

- Counterfeit currency: A major benefit of digital payment is that it reduce the threat and impact of counterfeit currency which is a great loss to the nation's economy.

\section{Challenges in the Usage of Mobile Based Payments for the Government Services}

There are many challenges considering the ecosystem of the government machinery and our society, some of them are:

- Government Processes: Though government is making lot of efforts in changing the process and policies to accommodate digital and mobile based payments, but still many of the department need to do the process re-engineering to simplify them.

- Limited literacy: There is a limited spread of financial and technical literacy, also business finance knowledge reduces the usage of mobile based payments.

- Mobile and Internet penetration: As per a report by the Internet and Mobile Association of India (IAMAI) out of 500 million internet users across India only 33\% users are from rural areas. Female internet users overall are approximately $30 \%$ of total Internet users.

- Technology Challenges: Mobile based payment are mostly done by the users having smartphones. Users owning the low cost key based are not very comfortable using the mobile phones for making payments. 
- Inclination for a physical brick and mortar branch: A large section of the rural population is not comfortable with mobile based banking and prefer a physical brick and mortar bank branch for trust.

- Data privacy and security issues: Citizens who are using the mobile based payment options are concerned of the privacy of the data and information which leads to lesser usage of such options.

- Cashless Benefit Transfers: Government departments which do not do the Cashless Benefit Transfers and are not linked to the online banking system also acts a deterrent to this system.

- Service charges: Transaction and Holding charges act as a restraining factor to the mobile based payments, particularly to older and low-income group section.

- Age related factor: Relatively young population are more potential section of society as compared to older generation, even these kind of mobile apps are more popular among young generation which leaves out a major chunk of population. Population in the age group of 12-29 years comprises of $2 / 3^{\text {rd }}$ of internet users in India.

- Gender divide: In between male and female population there is a comprehensive divide, moreover women do not have good affluence and this hinders access to mobile based payments. The report also indicates that there is a clear gender disparity when it comes to internet usage in India. The analysis notes that the female internet user is half of the 258 Million male internet users, and the bias is more evident in rural India.

- Legal identity: Legal identity or KYC norms are is a prerequisite to access mobile payment services, therefore in the case of economic and political expatriates and wandering workers more often due to lack of documents to institute legal identity becomes the cause of exclusion in this factor.

- Place of living: Unavailability of mobile service in relatively remote locations affect access to these services.

- Psychological and cultural barriers: The segment of society, especially low income group, older, ethnic minority at time have this perception that they are excluded from using financial services through mobile and this actually leads to self-exclusion.

\section{Conclusion}

As Government unquestionably will have to provide mobile payment options, it may be tested for sustenance of all of the upcoming and yet to arise platforms. Since these platform are controlled by the banks and credit card company's infrastructure the Government is likely to accept a subgroup of the available platforms. Citizens who are using the Government services are concerned of the privacy of the data and information. Government needs to evaluate the procedure from beginning to end to ensure it meets strict standards and keeps information private. There is a need of single unified portal among all the central, state governments and their public sector undertakings for the payment collection mechanism. Poor literacy levels are a problem with this technology. The mobile payment services have to be effective in terms of usability, cost, efficiency, interoperability and security for transactions of all categories of citizens. Mobile payments options needs to be available even on low end mobile handsets. 


\section{References}

[1] R Renjan, KamalAnju (2019) "Perception of Smartphone users Towards Mobile Payment System an Empirical Study", International Journal of Recent Technology and Engineering (IJRTE) ISSN: 2277-3878, Volume-8, Issue-1, May 2019

[2] P.Sarika, S.Vasantha (2019) "Impact of Mobile Wallets on Cashless Transaction", International Journal of Recent Technology and Engineering (IJRTE) ISSN: 2277-3878, Volume-7, Issue-6S5, April 2019

[3] Dr. Shilpa Bhimrao Gaonkar (2018) "Moving Towards Cashless India", SANSMARAN Management Research Journal, ISSN No. 2278-7801, Vol.8 No. 1.

[4] Dr. Shilpi Saraswat \& Dr. Mona Mehta (2017) "Cashless Transaction: Challenges faced by the Consumers" -International Journal of Research Culture Society, ISSN:2436-6683 Volume-1, Issue-10, Dec-2017, UGC Approved Monthly, Peer-Reviewed, Refereed, Indexed Journal Impact Factor: 3.449 Publication Date: 31/12/2017.

[5] Rakhi Thakur (2018) "Customer adoption of mobile payment services by professionals across two cities in India: An empirical study using modified technology acceptance model”, Business Perspectives and Research.

[6] Khushbu Madan \&Rajan Yadav (2016) "Behavioral Intention to adopt mobile wallet: a Developing country perspective", Journal of Indian Business Research, Vol. 8 No. 3, 2016 pp. 227-244 () Emerald Group Publishing Limited 1755-4195, DOI 10.1108/JIBR10-2015-0112.

[7] SubhoChattopadhyay, Payal Gulati \&Indranil Bose (2018) "Awareness and Participation of Small Retail Businesses in Cashless Transactions: An Empirical Study", Management Dynamics in the Knowledge Economy, Vol.6 (2018) no.2, pp.209- 225; DOI 10.25019/MDKE/6.2.02 ISSN 23928042 (online).

[8] Ruchi V. Dixit, Dr. R.N Singh \&Satyam Chaturvedi (2017) "A Study on Adoption of Mobile Wallet for Cashless Economy", IES Value Addition through Education, Anvesha, Vol. 10 No. 1.

[9] Alao, A. Adeniyi\&Sorinola, O. Olutayo (2015) "Cashless Policy and Customers' Satisfaction: A Study of Commercial Banks in Ogun State, Nigeria" Research Journal of Finance and Accounting www.iiste.orgISSN 2222-1697 (Paper) ISSN 2222-2847 (Online)Vol.6, No.2, 2015.

[10] http://cashlessindia.gov.in/index.html

[11] https://www.npci.org.in/statistics

[12] https://www.rbi.org.in/home.aspx

[13] https://inc42.com/buzz/internet-in-india-2019-equal-split-of-internet-users-in-rural-and-urbanareas/

[14] http://vikaspedia.in/e-governance/digital-payment/policies-and-schemes/promotion-of-paymentsthrough-cards-and-digital-means

[15] https://economictimes.indiatimes.com/https://economictimes.indiatimes.com/industry/banking/fin ance/banking/digital-payments-growing-in-india-at-12-7-cagr-

$\mathrm{kpmg} /$ articleshow/70890809.cms?utm_source=contentofinterest\&utm_medium=text\&utm_camp aign $=$ cppst

${ }^{*}$ Corresponding author.

E-mail address: ashishiaiswal01@gmail.com 